\title{
Development of a consultation and teaching concept for leg wound treatment in home health care
}

\author{
Ann-Marie Jönsson* and Ania Willman ${ }^{\dagger}$ \\ *School of Health and Society, Malmö University, Malmö; ‘School of Health Science, Blekinge Institute of Technology, \\ Karlskrona, Sweden
}

\begin{abstract}
Summary
We developed a consultation and teaching concept about leg wounds and their care, for use by patients and caregivers in a home health-care setting. Descriptive data were gathered through a survey distributed to three groups, comprising 21 individuals (18 nurses and 3 health administrators). These participants provided answers regarding group activities, meeting frequency, meeting notes and meeting content, as well as responses to questions regarding the Website, Web materials, film and a pamphlet. Seventeen people answered the survey ( $81 \%$ response rate). They made predominantly positive comments. The combined total average score was 3.6 $(1=$ very bad to $4=$ very good). The concept was implemented in one municipality in a health-care region in southern Sweden using high bandwidth videophones $(640 \mathrm{kbit} / \mathrm{s})$. The results showed that elderly persons at home and nurses working in home health care were interested in using the concept and communicating via videophone. A strength of the Web-based information and communication material is its adaptability to suit both patients and care givers.
\end{abstract}

\section{Introduction}

Leg wounds are wounds on the lower legs with varied aetiology ${ }^{1}$ that do not heal within six weeks. They constitute a multidisciplinary problem. In Sweden 50,000 individuals have open leg wounds and require over five million dressings per year. ${ }^{2}$ Two percent of the population has had a leg wound. The cost of treating leg wounds in Sweden including dressings, surgical interventions and preventative compression treatments, ${ }^{3}$ amounts to approximately 2.3 billion Swedish crowns annually ( 32 million US dollars). The age group most affected by leg wounds that do not easily heal are the elderly who are often cared for in the municipal home health-care system.

Home health care is the term for health care and other coordinated care interventions for patients in their homes. Since most elderly people prefer home health care to institutional care it is necessary for nurses to develop knowledge-based and cost-effective work methods for accomplishing these practical care tasks. ${ }^{4}$

Video-based communication between the patient and the home health-care team can offer effective care of acceptable quality. ${ }^{5}$ Computer support offers the opportunity to integrate patient-related content with teaching material. ${ }^{6} \mathrm{~A}$ few studies have used telephonecare to address patients' every day situations, e.g. the ACTION project. ${ }^{7}$ We have examined a Web-based consultation and teaching concept offering education for both patients and caregivers. The research question to be answered was: what obstacles and possibilities occur in developing such a project for care of the elderly?

\section{Methods}

The study was approved by the appropriate ethics committee. Descriptive data were gathered through a survey distributed to three groups, comprising 
21 individuals (18 nurses and 3 health administrators). These participants provided answers regarding group activities, meeting frequency, meeting notes and meeting content, as well as responses to questions regarding the Website, Web materials, film and a pamphlet. The answers were scored on a four-point Likert scale $(1=$ very bad to $4=$ very good $)$. Notes from the group participants were continually collected from the shared Website where meeting notes, study materials and discussion questions were published.

The 35 regional participants in the introductory seminar were able to contribute with notes. The most frequent notes came from the participants in the steering group and four of the working groups. The project leader continually wrote memoranda. The survey replies were analysed with descriptive statistical methods. All notes were processed and analysed with the manifest method ${ }^{8}$ and the themes extracted.

\section{Results}

\section{Preparatory work}

A steering committee was established, consisting of eight members. One participant, the project leader, was given the responsibility of coordinating the various interventions. The work process began with an inventory and an invitation to a seminar, as well as the creation of work groups. Mapping at the national level was carried out on the Internet in order to establish knowledge about which provincial care areas had wound care programmes. The inventory showed that within the southern care region 17 different wound care groups existed for the care of wounds and as many programmes for wound care. The care programmes for wound care were all different in scope, from inclusion of the entire wound care area to limited areas such as pressure wounds, diabetic foot sores or leg wounds. Often these programmes were documented on paper, but a few were also published on the Internet. In addition, four telephone interviews were performed. Local wound care groups within the southern healthcare region were invited to an introductory seminar. Fourteen groups altogether, including 35 individuals, participated and discussed the topic area as well as what limitations ought to be in effect for the concept and the Web material.

\section{Development process}

Six working groups, which included the 21 participants in the original three groups, began to work with different parts of the Web-based consultation and teaching concept, and to prepare the technology for video communication (Table 1). Groups named 'leg wounds', 'teacher', 'test', 'control' and 'IT expert' worked for about one year. The group 'consultants/ experts' worked for four months. The group meetings varied in length. The meetings of the 'leg wounds' and 'teacher' groups' entailed whole days, while the others required parts of days. The group 'leg wounds' had the biggest task since that group produced the Web-based material. The 'control' and 'test' groups prepared the implementation of the concept. All meetings were documented and published on the network's Website.

Table 1 Overview of the working groups

\begin{tabular}{|c|c|c|c|c|}
\hline Group & Number of members & Tasks & $\begin{array}{l}\text { Time } \\
\text { period }\end{array}$ & Meetings \\
\hline Leg wounds & $\begin{array}{l}8 \text { members: } 5 \text { registered nurses, a physician, a } \\
\text { licensed practical nurse as well as the project } \\
\text { leader. }\end{array}$ & $\begin{array}{l}\text { Developed the content of the consultation and } \\
\text { teaching concept. Participated in working } \\
\text { meetings and contributed professional } \\
\text { expertise. Reported on completed work as well } \\
\text { as risk for deviations. Documented goals } \\
\text { accomplished. }\end{array}$ & 1 year & 6 \\
\hline Teachers & $\begin{array}{l}7 \text { members: } 6 \text { representatives for college/ } \\
\text { university teachers in the health-care field and } \\
\text { the project leader. }\end{array}$ & $\begin{array}{l}\text { Advised about informational and educational } \\
\text { interventions for the patients, next of kin and } \\
\text { health-care personnel as well as for the project } \\
\text { leader. Edited Web material. }\end{array}$ & 1 year & 3 \\
\hline Test & $\begin{array}{l}4 \text { participants: a patient, a registered nurse, a } \\
\text { licensed practical nurse and the project leader. }\end{array}$ & Planned for implementation. & 1 year & 4 \\
\hline Control & $\begin{array}{l}4 \text { participants: a patient, a registered nurse, } \\
\text { a licensed practical nurse and the project } \\
\text { leader. }\end{array}$ & Planned for implementation. & 1 year & 3 \\
\hline $\begin{array}{l}\text { Consultant/ } \\
\text { expert }\end{array}$ & $\begin{array}{l}5 \text { participants: } 3 \text { physicians with expert knowledge } \\
\text { and the project leader as well as the director of } \\
\text { the management group. }\end{array}$ & Provided medical expertise for consultation. & 4 months & 2 \\
\hline IT expert & $\begin{array}{l}5 \text { participants: } 3 \text { IT-knowledgeable persons within } \\
\text { region as well as a nurse and the project } \\
\text { leader. }\end{array}$ & Specified the technological requirements. & 1 year & 2 \\
\hline
\end{tabular}




\section{Content}

A cross-professional group, named 'leg wounds', consisting of physicians, registered nurses and a licensed practical nurse, developed the Web material in collaboration with the project leader. The Website (http://www.skane.se/bensar) had two main versions:

- a simplified version for patients and next of kin with nutritional and exercise advice and information about wound treatment and dressing;

- a more illustrated and in-depth version about leg wounds and their treatment open to all health-care personnel and intended to be utilized in their daily work.

A common glossary, a list of sources, related links and a description of the project was added to both of these versions (Figure 1). The version intended for patients and their next of kin contained concrete advice and its importance for well-being, as well as detailed information regarding the care and dressing of leg wounds. The version aimed at health-care personnel contained detailed material combined with knowledge-based care and treatment advice, that was to be applied in the daily work of home health care.

During the preparatory work, a film and a brochure were developed for use in spreading information about the consulting and teaching concept. All the individuals portrayed in the film and in the brochure gave their consent to publication. The film was five minutes in length and described the content and execution of the concept. One of the patients and her next of kin participated in the film and an outsider narrated. The brochure included pictures of the same couple featured in the film and one of the nurses from

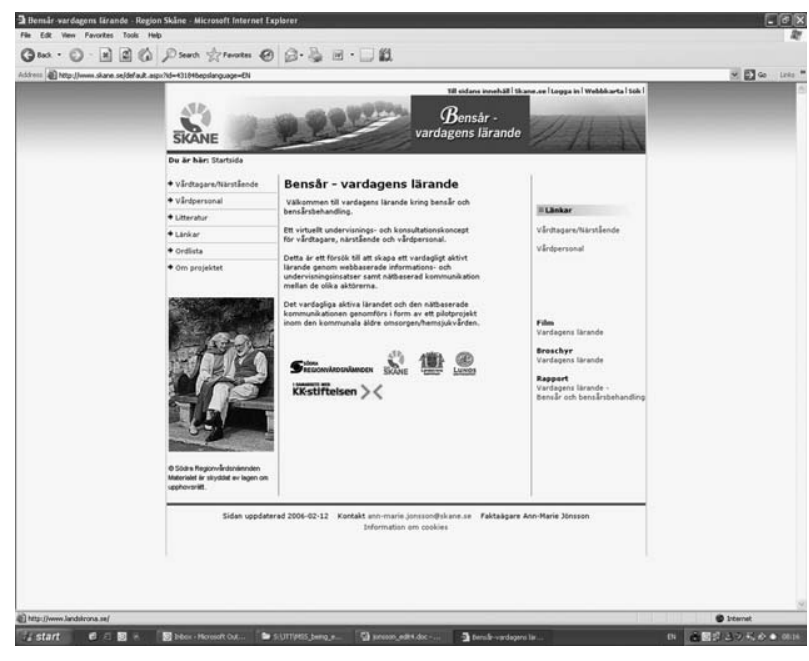

Figure 1 Home page for the Website Leg Wounds: Everyday Learning (http://www.skane.se/bensar) home health care. The text in the brochure was organized under headings such as Every-day Learning, Communication, Web Material and the Vision of the Concept.

\section{Videophone communication}

The concept was implemented in one municipality in a health-care region in southern Sweden. As leg wounds are common among the elderly, who typically do not have their own computer nor computer experience, interactive communication was used with the help of a videophone (Figures 2 and 3). The videophone (640 series, VisionTech - see http://www.visiontech.se) was connected at a bandwidth of $640 \mathrm{kbit} / \mathrm{s}$. This required access to a broadband Internet connection in the patient's home. The nurses' videophones were connected to their existing computer equipment.

Oral and written information was given to the patient and caregiver 3-4 weeks before using the videophone. At the outset of the interactive communication, the oral information was repeated.

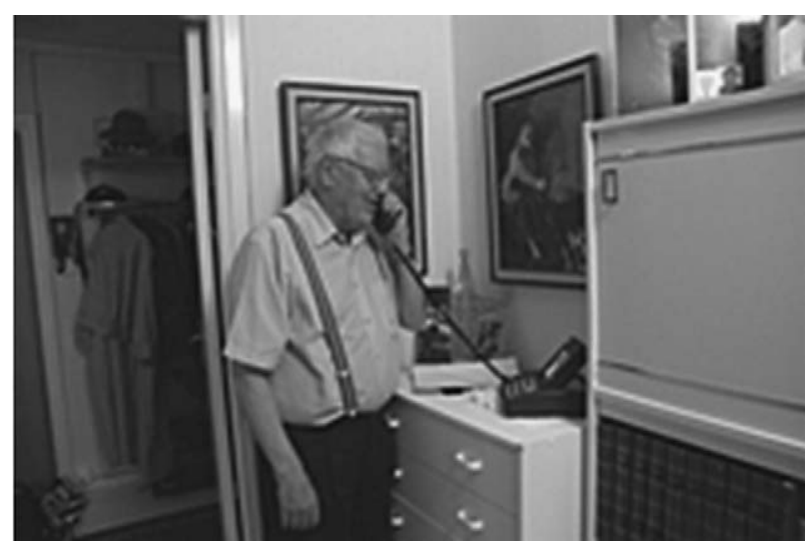

Figure 2 Next of kin making a connection with the videophone

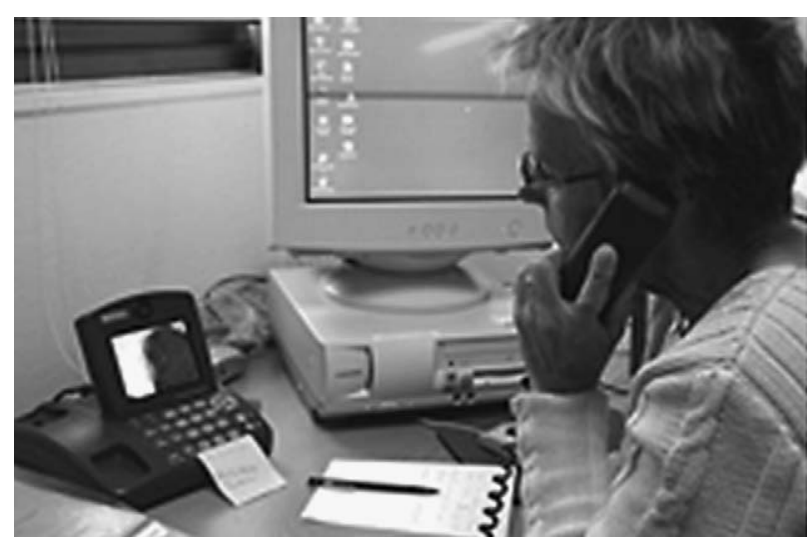

Figure 3 Nurse replying with the videophone 
Initially there was a consulting group, made up of representatives from the videophone company, the municipal network technicians and a nurse from the home health-care system as well as the project leader, available to provide support to patients and caregivers. The project leader, in consultation with the municipal nurse in charge of home health care, maintained contact with patients and health-care workers throughout the project.

\section{Implementation}

Six videophones were used. The videophones were connected to the patient's own television set because it produced a bigger image than the one shown on the videophone's display screen. Health-care personnel in the municipality had access to the Web material through the project Website. As the patients did not have computers they could not connect to the Website. However, the nurse in charge could show parts of the Web-based material to patients and their next of kin via the videophone and/or by playing it on the TV set.

\section{Views of the participants}

Ninety-eight percent of the group members (including local wound care groups) had read the materials on the Website, but few used it to leave comments or ask questions. Most patients experienced technical problems with image and sound transmission. These problems were related to the connection of videophones to the computer networks.

The survey was distributed to 21 individuals and 17 replied ( $81 \%$ response rate). They made predominantly positive comments. The combined total average score was 3.6 (range 3.3-3.9), see Table 2.

The participants in the steering committee considered that the concept was good and that it had great potential, although there were some technical difficulties to be overcome. These difficulties were felt to be rooted more in the regional and municipal structures than in other parts of the concept. The

Table 2 Survey replies $(n=17)$

\begin{tabular}{lc}
\hline Area & Average score* \\
\hline Activity of the group & 3.5 \\
Number of meetings & 3.9 \\
Meeting notes & 3.8 \\
The group's work as a whole & 3.4 \\
Web workplace & 3.9 \\
Film & 3.3 \\
Brochure & 3.8 \\
The project organization as a whole & 3.4 \\
\hline
\end{tabular}

*1=very bad, 2=bad, 3=good, 4=very good participants in the 'leg wound' group stated that it was productive to be given an opportunity to participate in the development of the concept, and they wished that it would become the support for various health-care levels that the group had worked for. They also felt that it was a very positive experience to take part in a project with direct practical applications. In addition it was educational and inspirational to work alongside competent individuals. The 'teacher' group opined that it was useful to work with individuals who were deeply committed to wound care and that they would be able to improve future nurse education regarding leg wounds and their treatment by adapting the curriculum to Web-based teaching.

\section{Discussion}

The organization for the development and implementation of the concept, consisting of a steering committee and working groups, worked well for the various tasks. Those with expertise on the issue within the groups 'leg wounds' and 'teacher' participated in creating Web materials about leg wounds and their treatment. Although 98\% of the participants had read the materials on the Web, only a few took advantage of the opportunity to provide comments and suggestions. One reason for this might have been their lack of experience in using the Internet as means of communication. Technical problems occurred for most of the patients.

The strength of the concept lay in the fact that the same materials included information and knowledge for both patients and caregivers. For the caregivers there were also referrals to in-depth follow-up. Patients who were interested could partake of this in-depth information and discuss it with the caregivers. Next of kin could also participate in discussions about treatment.

The test group was informed about the technology and practiced using the videophone. What was significant for the continuation of the work was whether the elderly subjects were interested in participating in the concept and had access to the new method of communication. ${ }^{4}$ Earlier studies have shown that videophone communication is useful, acceptable and gives better qualitative and more effective care. ${ }^{5,6}$

The experience from the present study showed that the concept had great potential. But consideration needs to be paid to the lack of experience with videocommunication, amongst both patients and caregivers. This may require a longer period of training in future work. However, it is clear that when properly utilized, 
information technology has great potential to support high quality care in work with patients. ${ }^{9}$

Since 1998 there have been evidence-based guidelines ${ }^{10}$ for leg wounds, but these are still largely unknown to health-care personnel despite the many wound care groups which exist, both nationally and regionally. The multiplicity of groups shows the level of interest in the issue and suggests that there is a wealth of experience-based knowledge. ${ }^{11}$ This collected knowledge should be able to serve as a basis for national guidelines on the issue. One way to gather this experiential knowledge through the Internet is to create a network for discussions. One way to disseminate knowledge and information through the Internet is to arrange seminars on 'Everyday Learning: Leg Wounds and Their Care'. The present study showed that Internet-based material and communication can be an asset in patient care at home. The concept could be applied in other applications, for example for those caring for the skin of extremely premature babies. ${ }^{12}$

\section{References}

1 Lindholm C. Sår. [Wound Care] 2:a uppl. Lund: Studentlitteratur 2003
2 Nelzen O, Bergqvist D, Lindhagen A. The prevalence of chronic lower-limb ulceration has been underestimated: results of a validated population questionnaire. Br J Surg 1996;83:255-8

3 Ragnarsson Tennvall G, Andersson K, Bjellerup M, Hjelmgren J, Öien R. Venösa bensår kan behandlas både bättre och billigare. Beräkning av årliga kostnader baserad på en enkätstudie [Treatment of venous leg ulcers can be better and cheaper. Annual costs calculation based on an inquiry study]. Läkartidningen 2004;101:1506-3

4 Arnaert A, Delesie L. Telenursing for the elderly. The case for care via video-telephony. J Telemed Telecare 2001;7:311-16

5 Nicolas L, Franco A, Provost H, et al. Videophone assistance and home hospitalization: The ViSaDom program. Presse Med 2005;34:1059-64

6 Adamsen L, Larsen K, Bjerregaard I, Madsen JK. Danish researchactive clinical nurses overcome barriers in research utilization. Scand J Caring Sci 2003;17:57-65

7 Magnusson L, Berthold H, Chambers M, Brito L, Emery D, Daly T. Using telematics with older people: the ACTION project. Assisting Carers using Telematics Interventions to meet Older persons' Needs. Nurs Stan 1998;13:36-40

8 Berg BL. Qualitative Research Methods for the Social Sciences. 5th edn. Boston: Pearson/Allyn and Bacon, 2004

9 Heinzelmann PJ, Lugn NE, Kvedar JC. Telemedicine in the future. $J$ Telemed Telecare 2005;11:384-90

10 Scottish Intercollegiate Guidelines Network. See http:// www.sign.ac.uk (last checked 9 October 2006)

11 Willman A, Stoltz P. Evidensbaserad omvairdnad - en bro mellan forskning och klinisk verksamhet [Evidence-based care: A bridge between research and clinical practice]. Lund: Studentlitteratur, 2002

12 Extremt för tidigt födda barns hud. See http://www.skane.se/ neonatalvard (last checked 5 November 2006) 